\title{
Leber Congenital Amaurosis Caused by Mutations in GUCY2D
}

\author{
Shannon E. Boye \\ Department of Ophthalmology and Department of Molecular Genetics and Microbiology, University \\ of Florida College of Medicine, Gainesville, Florida 32610 \\ Correspondence: shannon.boye@eye.ufl.edu
}

Leber congenital amaurosis (LCA) is a clinically and genetically heterogeneous group of diseases that account for the most severe form of early-onset retinal dystrophy. Mutations in retinal guanylate cyclase-1 (GUCY2D) are associated with LCA1, a prevalent form. GUCY2D encodes guanylate cyclase-1 (GC1), a protein expressed in rod and cone photoreceptors that regulates cGMP and $\mathrm{Ca}^{2+}$ levels within these cells. LCA1 patients present with severely impaired vision, reduced, or ablated electroretinogram and nystagmus. Despite a high degree of visual disturbance, LCA1 patients retain normal photoreceptor laminar architecture, except for foveal cone outer segment abnormalities and, in some patients, foveal cone loss. This article will summarize clinical characterization of patients and proof of concept gene replacement studies in several animal models of GC1 deficiency, both of which have laid the groundwork for clinical application of a gene therapy for treatment of LCA1.

eber congenital amaurosis (LCA) is a clinLically and genetically heterogeneous group of early-onset blinding diseases (den Hollander et al. 2008). There are currently 18 genes known to be associated with LCA, each of which encodes a retinal protein with unique function. Guanylate cyclase-1 (GUCY2D) was the first gene found to be associated with the disease and was thus assigned the LCA1 locus (Perrault et al. 1996). Mutations in this gene are a leading cause of LCA, accounting for $10 \%-20 \%$ of all cases (Perrault et al. 2000). GUCY2D encodes guanylate cyclase-1 (GC1), a protein expressed exclusively in the outer segments of photoreceptors (predominantly cones) in the vertebrate retina (Fig. 1) (Dizhoor et al. 1994; Liu et al. 1994).
To understand why mutations in GUCY2D lead to disease, one must first understand how GC1 normally contributes to the ability to see. The process of vision begins with absorption of a photon of light by a visual pigment, rhodopsin or cone opsin, in the outer segments of rod and cone photoreceptors, respectively. This interaction initiates a biochemical cascade referred to as "phototransduction." On light stimulation, cyclic guanosine monophosphate (cGMP) is hydrolyzed by cGMP phophodiesterase, leading to closure of cGMP-gated channels, reduction of intracellular $\mathrm{Ca}^{2+}$ and hyperpolarization of the photoreceptor. It is this reduction of intracellular calcium/hyperpolarization that signals the "recovery phase" of phototransduction

Editors: Eric A. Pierce, Richard H. Masland, and Joan W. Miller

Additional Perspectives on Retinal Disorders: Genetic Approaches to Diagnosis and Treatment available at www.perspectivesinmedicine.org

Copyright (C) 2015 Cold Spring Harbor Laboratory Press; all rights reserved; doi: 101101/cshperspect.a017350 Cite this article as Cold Spring Harb Perspect Med 2015;5:a017350 
S.E. Boye

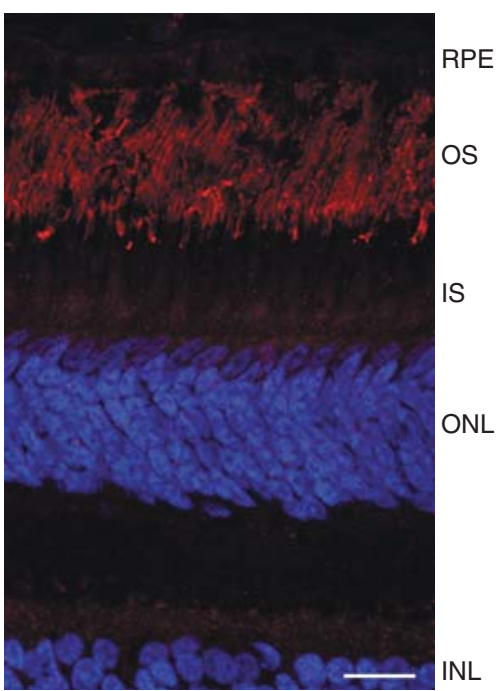

Figure 1. GC1 expression (red) in photoreceptor outer segments of a nonhuman primate retina. Frozen retinal cross sections were stained for GC1 and counterstained with DAPI. RPE, retinal pigment epithelium; OS, outer segments; IS, inner segments; ONL, outer nuclear layer; INL, inner nuclear layer. Scale bar, $7 \mu \mathrm{m}$.

and resets the sensitivity of photoreceptors. Photoreceptors of vertebrate species possess two guanylate cyclases (GC1 and GC2) (Lowe et al. 1995) and two guanylate cyclase activating proteins (GCAPs), GCAP1 and GCAP2 (Dizhoor et al. 1995; Gorczyca et al. 1995). GCAPs function as $\mathrm{Ca}^{2+}$ sensors that regulate activity of the guanylate cyclases. In the dark-adapted photoreceptor, $\mathrm{Ca}^{2+}$ binds GCAP1 and GCAP2, which collectively inhibit the activity of retinal GC1 and GC2. On light stimulation/hyperpolarization, $\mathrm{Ca}^{2+}$-free GCAPs stimulate the activity of GCs, resulting in an increase in cGMP, reopening of the cGMP-gated channels, influx of $\mathrm{Ca}^{2+}$, and return of the photoreceptor to its depolarized dark-state (Burns and Arshavsky 2005; Arshavsky and Burns 2012). In vivo, GC1 is the preferred target of GCAP1 (Olshevskaya et al. 2012). In vitro, however, GCAP1 and GCAP2 can activate both GCs, albeit with slightly different affinities and sensitivity to $\mathrm{Ca}^{2+}$ (Hwang et al. 2003; Peshenko and Dizhoor 2004; Peshenko et al. 2011). Mutations that reduce or abolish the ability of GC1 to replenish cGMP in photoreceptors are thought to lead to the biochemical equivalent of chronic light exposure in these cells. There are no reported cases of human disease involving mutations in GUCY2F (the gene encoding GC2). Deletion of GC2 from the rodent retina has little effect on retinal function (Baehr et al. 2007).

\section{PATIENT CHARACTERIZATION}

LCA1 patients present within the first year of life and are routinely described as having reduced visual acuity, reduced or nonrecordable electroretinogram (ERG) responses, nystagmus, digito-ocular signs, and apparently normal fundus (Perrault et al. 1999; Chung and Traboulsi 2009). Reports on the extent of photoreceptor degeneration associated with this disease have been conflicting. Histopathological analysis of two postmortem retinas (a 26 -wk-old preterm abortus and a 12-yr-old donor) revealed signs of photoreceptor degeneration in both rods and cones (Milam et al. 2003; Porto et al. 2003). Later studies using state of the art, in-life imaging (i.e., optical coherence tomography) revealed no obvious degeneration in patients as old as 53 years of age (Simonelli et al. 2007; Pasadhika et al. 2010).

The most recent and thorough clinical characterization of LCA1 to date involved a cohort of patients ranging in age from $6 \mathrm{mo}$ to $37 \mathrm{yr}$ with different GUCY2D mutations, and has shed new light on the effects of GC1 deficiency on retinal structure and function (Jacobson et al. 2013). In agreement with previous imaging studies (Simonelli et al. 2007; Pasadhika et al. 2010), Jacobson et al. (2013) report that LCA1 patients retain normal photoreceptor laminar architecture aside from foveal cone outer segment abnormalities and, in a few patients, foveal cone loss. Outer nuclear layer and photoreceptor outer segment thickness measurements in the rod-dominant retina (i.e., outside the fovea) were normal in all patients evaluated. Contrary to previous ERG findings, Jacobson et al. report that substantial rod function can be retained in LCA1. Under dark-adapted conditions, rod sensitivity thresholds in the majority of patients were approximately 0.5 to $5 \mathrm{log}$ units below that of normal. Full-field stimulus 
testing using blue stimuli to isolate rod responses revealed that substantial rod function remained. There was no relationship between patient age and presence of rod function. Patients with retained rod function successfully avoided obstacles in a dimly lit mobility course, revealing that rod function translates to useful vision in these cases. In contrast to the findings for the rods, ERG analysis revealed that cone function was undetectable in all LCA1 patients evaluated. Psychophysical tests revealed that the majority of patients lacked cone-mediated vision. This correlated with severely reduced visual acuity and a lack of color perception. Full-field stimulus testing, microperimetry and mobility tests revealed that a small subset of patients (four out of 11) had detectable but reduced cone function, with central fixation and some color perception.

To understand why residual, yet abnormal, cone function remained in only a subset of LCA1 patients, an elegant biochemical analysis of GC activity was performed. Human embryonic kidney (HEK293) cells were transfected with either wild-type or patient-specific GC1 mutants. Activity assays were performed by supplying cells with GCAPs under ionic conditions best suited for GC1 activity (Jacobson et al. 2013). The amount of cGMP produced by each mutant was quantified and compared relative to that produced by wild-type GC1. Not surprisingly, mutants showing biochemical evidence of catalytic activity in vitro were those expressed by patients with measurable cone function. Of these mutants, some had reduced catalytic activity (four- to fivefold lower than wild-type), whereas others demonstrated no loss-of-function in vitro. These mutations might cause defective folding, altered expression or impaired trafficking to the proper compartment of the living photoreceptor, the outer segment. However, definitive conclusions cannot be drawn until in vivo studies are performed. As expected "null" mutations that rendered GC1 biochemically inactive corresponded to patients with profound loss of cone function (Jacobson et al. 2013).

Taken together, it is now apparent that GUCY2D-LCA1 is unique from other forms of
LCA studied in detail to date (Jacobson et al. 1998, 2003, 2005, 2007a,b, 2009, 2011; Cideciyan et al. 2007). The hallmark retinal preservation observed suggests that LCA1 is an attractive target for gene augmentation therapy and that patient retinas may better withstand the surgical manipulation of a subretinal injection. The profound visual impairment, stemming predominantly from a loss of cone function, points to the fovea as the target for treatment. In the minority of patients lacking foveal cones, the parafoveal or perifoveal retina may be targeted in the hopes that eccentric fixation will occur, as was seen in some patients in LCA2 clinical trials (Cideciyan et al. 2009). Careful consideration must be given to outcome measures when treating patients with such profound visual impairment. Tests, which control for nystagmus, such as microperimetry, can be used to assess cone-mediated central vision (Cideciyan et al. 2012), along with standard visual acuity measurements. Full-field stimulus testing, an assay for which the limits of variability have been defined in LCA patients, can be used to identify any localized improvements in rod function. Optical coherence tomography can be used both to monitor the safety of subfoveal injection and to look for any improvements in cone outer segment morphology following treatment.

\section{PROOF OF CONCEPT STUDIES IN ANIMAL MODELS OF GC1 DEFICIENCY}

Work to characterize multiple animal models of GC1 deficiency began in the 1980s. Thirty-four years later, all models have been successfully used to evaluate proof of concept for gene replacement to treat GUCY2D-LCA1. Below is a summary of findings for each model.

\section{GUCY1*B Chicken}

The retinal degeneration ( $r d$ ) chicken, also referred to as the GUCY $1^{*} \mathrm{~B}$ chicken, was the first animal model of GC1 deficiency to be described (Cheng et al. 1980; Ulshafer et al. 1984; Ulshafer and Allen 1985a,b). This naturally occurring, cone-dominant, avian model carries a deletion/insertion mutation in the gene encoding 
S.E. Boye

GC1. Exons 4-7 of the gene are replaced by an 81 bp fragment with $89 \%$ sequence identity to a portion of exon 9 , in reverse orientation (Table 1). Although its reading frame is not disrupted, the mutant protein is predicted to lack a membrane spanning domain, the region essential for proper folding and enzyme activity (Polans et al. 1996). Antibodies raised against epitopes outside this deletion failed to detect any mutant protein expression in GUCY1*B chickens, suggesting that the protein is rapidly degraded. It is therefore considered to be a null allele (Semple-Rowland et al. 1998). Cyclic GMP levels in photoreceptors of posthatch day $1 \mathrm{GUCY} 1{ }^{*} \mathrm{~B}$ chickens are only $\sim 10 \%-20 \%$ of those observed in age-matched, wild-type controls. Af-

Table 1. Genetic bases for disease in animal models of LCA1

\begin{tabular}{|c|c|c|}
\hline & Mutation & $\begin{array}{c}\text { Effects on GC1 } \\
\text { protein }\end{array}$ \\
\hline $\begin{array}{c}\text { GUCY } 1^{*} B \\
\text { chicken }\end{array}$ & $\begin{array}{l}\text { Naturally occurring } \\
\text { deletion/ } \\
\text { insertion: Exons } \\
4-7 \text { replaced by } \\
\text { an } 81 \text { bp fragment } \\
\text { with homology } \\
\text { with sequence in } \\
\text { exon } 9 \text {, in reverse } \\
\text { orientation }\end{array}$ & $\begin{array}{l}\text { No functional } \\
\text { enzyme } \\
\text { produced, } \\
\text { null }\end{array}$ \\
\hline $\begin{array}{l}\text { GC1KO } \\
\text { mouse }\end{array}$ & $\begin{array}{l}\text { Engineered: } \\
\text { Disruption of } \\
\text { exon } 5 \\
\text { (transmembrane } \\
\text { domain region) } \\
\text { with neomycin } \\
\text { resistance cassette }\end{array}$ & $\begin{array}{l}\text { No functional } \\
\text { enzyme } \\
\text { produced, } \\
\text { null }\end{array}$ \\
\hline $\begin{array}{l}\text { GC1/GC2 } \\
\text { DKO } \\
\text { mouse }\end{array}$ & $\begin{array}{l}\text { Mouse engineered: } \\
\text { Disruption of } \\
\text { exon } 2 \\
\text { (containing } \\
\text { translation start } \\
\text { codon and } \\
\text { peptide leader } \\
\text { sequence) with } \\
\text { neomycin } \\
\text { resistance } \\
\text { cassette. Mice } \\
\text { then crossed to } \\
\text { GC1KO }\end{array}$ & $\begin{array}{l}\text { No functional } \\
\text { enzyme } \\
\text { produced, } \\
\text { null also } \\
\text { no functional } \\
\text { GC2 }\end{array}$ \\
\hline
\end{tabular}

fected chickens are blind at hatch, lacking any signs of reflexive or volitional behavior, and have nonrecordable ERG responses (Ulshafer et al. 1984). The reduction in cGMP and lack of visual behavior/retinal function are evident before loss of photoreceptors, which do not begin degenerating until 1 wk posthatch (Cheng et al. 1980; Ulshafer et al. 1984). Photoreceptor loss proceeds from the central to the peripheral retina (Ulshafer and Allen 1985a). Cones, which degenerate first, are completely lost by $\sim 3.5 \mathrm{mo}$. Rod loss follows, with all photoreceptors lost by $\sim 8$ mo (Ulshafer and Allen 1985a,b).

With the goal of providing therapy as early as possible, an in ovo treatment paradigm was developed to treat the GUCY $1{ }^{*} \mathrm{~B}$ chicken. For its ability to stably transduce retinal progenitor cells (Miyoshi et al. 1997), HIV-1-based lentivirus was used to deliver a cDNA encoding bovine GC1 to the neural tube of embryonic day 2 chickens via a small, $5 \mathrm{~mm}$ opening in the eggshell and membrane overlying the embryo (Williams et al. 2006; Semple-Rowland and Berry 2013). The therapeutic vector was bicistronic, with GC1 expression mediated by the ubiquitous elongation factor $1 \alpha$ promoter and enhanced green fluorescent protein (GFP) expression coupled to a poliovirus internal ribosome entry site (Williams et al. 2006). Enhanced green fluorescent protein was included in the vector because GC1 expression cannot be reliably detected in the chicken retina. The activity of bovine GC1 in the presence of chicken GCAPs was verified in vitro before treatment (Williams et al. 2006). Posthatch chicks were subjected to behavioral analyses and ERG, and their tissues were subsequently collected for histological and molecular analyses.

Treated GUCY $1^{*} \mathrm{~B}$ chickens were tested for the presence of an optokinetic reflex (Wallman and Velez 1985) and volitional visual behavior beginning at 3-7 $\mathrm{d}$ posthatch and every few days thereafter until $\sim 5$ wk of age (Williams et al. 2006). Results were compared with those seen in untreated GUCY1*B and wild-type controls. Six of the seven treated chickens showed some degree of sight during the course of the study, and five of these six showed optokinetic reflexes and volitional visual behavior 
Gene Therapy for GUCY2D LCA1

up to the end of the study; in the sixth, visual function decreased during the last week of the study. ERG analyses revealed that the five treated chickens that showed sighted behavior at the end of the study displayed modest increases in a- and b-wave amplitudes (to $6 \%$ of wild-type) under both dark- and light-adapted conditions. Quantitative genomic PCR revealed the presence of integrated transgenes in all six retinas from the treated birds that had shown sight, and that the transcript number was correlated with the degree of treatment effect. Immunohistochemical analysis of GFP expression in treated retinas revealed spotty expression of transgene throughout the photoreceptor cell bodies and possibly inner and outer segments. Histological analysis of treated, untreated, and wild-type retinas revealed that lentiviral-mediated GC1 expression slowed but did not prevent photoreceptor degeneration in affected chickens.

Results of this GUCY1* B chicken study were exciting proof of concept, albeit in a nonmammalian model, that gene replacement could be effective for treatment of LCA1. However, rescue effects noted in this and a more recent study incorporating a modified, bicistronic lentiviral vector were transient, with data only reported out to $5 \mathrm{wk}$ posthatch (Williams et al. 2006; Verrier et al. 2011). Indeed, the therapeutic effect observed by Williams et al. was transient, with behavioral responses disappearing in treated GUCY1*B chickens beyond the time points discussed in that study (unpublished findings). Furthermore, results in the chicken studies were obtained following embryonic vector delivery, a currently untenable task in patients. Neural tube delivery did not allow for evaluation of an internal, untreated control because both retinas were transduced. Last, lentiviral vectors, although useful for transduction of retinal precursors, have demonstrated little to no ability to transduce the disease target in LCA1-postmitotic photoreceptors (Miyoshi et al. 1997; Bainbridge et al. 2001; Pang et al. 2006). Taken together, this highlighted the need for a more translatable animal model and gene replacement strategy with which to address a treatment for this disease.

\section{GC1KO Mouse}

In 1999, the Garbers laboratory published natural history data on the first engineered, mammalian model of GC1 deficiency, the Gucy $2 e^{\mathrm{tm} 1 \mathrm{Gar}}$ mouse, which is commonly referred to as the GC1 knockout (GC1KO) mouse (Yang et al. 1999). Insertion of a neomycin resistance cassette into exon 5 of Gucy $2 e$ (the murine homolog of GUCY2D) truncates GC1, rendering it null (Table 1). Western blot analysis confirmed the absence of GC1 protein and that levels of GC2 remained unchanged. Cone photoreceptors in the GC1KO mouse degenerate rapidly beginning at $4-5 \mathrm{wk}$, at a rate comparable to that seen in the GUCY $1{ }^{*}$ B chicken. Loss of cone function precedes cone degeneration; cone-mediated ERG responses are barely detectable at this age. Rods do not degenerate, however, and continue to respond to light, albeit with variable and reduced amplitudes (30\%-50\% of wild-type). It is now known that this residual rod function is attributed to the presence of GC2 in these cells (Baehr et al. 2007). Subsequent immunohistochemical analyses of this mouse model revealed that both GCAP1 and GCAP2 are down-regulated in 4-wk-old GC1KO retinas, and GCAP1 expression is undetectable in photoreceptor outer segments of frozen retinal sections (Coleman et al. 2004). Additionally, it was found that cone arrestin translocation, a biochemical correlate of functionality, is disrupted in GC1KO cones, further supporting the notion that these cells are unable to reset their light signaling cascade (Coleman and Semple-Rowland 2005).

For its proven ability to transduce postmitotic rodent photoreceptors following subretinal injection (Yang et al. 2002), a serotype 5 adeno-associated virus (AAV5) was chosen to deliver therapeutic cDNA to the GC1KO mouse. Initial experiments, conducted by some of the same investigators working on the chicken model, also incorporated a bovine GC1 cDNA (Haire et al. 2006). Cell-specific (mouse opsin) and ubiquitous (smCBA, a truncated version of the CBA promoter, which is a fusion of the chicken $\beta$-actin promoter and the CMV immediate-early cytomegalovirus enhancer) promoters were selected to drive transgene expression 
S.E. Boye

(Haire et al. 2006). Treatment by subretinal injection at postnatal day $(\mathrm{P}) 21$ with either AAV5MOP-bGucy2d or AAV5-smCBA-bGucy2d $\left(\sim 1 \times 10^{9}\right.$ vg delivered) failed to restore rod or cone function to treated GC1KO mice, as assessed by full-field ERG (Haire et al. 2006). The only therapeutic effect observed in this initial experiment was a restoration of lightdriven arrestin translocation in cone photoreceptors expressing AAV-mediated bGC1 (Haire et al. 2006).

In subsequent experiments, Boye et al. explored whether the lack of robust rescue noted above was owing to the species nonspecific nature of the delivered transgene. Indeed, subretinal delivery of murine Gucy2e with AAV5 containing either the smCBA or photoreceptor-specific, human rhodopsin kinase (hGRK1) promoter (Khani et al. 2007) led to robust rescue of the GC1KO phenotype (AAV5-smCBAGucy2e, $4 \times 10^{10}$ vg delivered; AAV5-hGRK1Gucy2e, $4 \times 10^{10}$ vg delivered; [Boye et al. 2010]). AAV-mediated GC1 expression was found exclusively in rods and cones of treated mice, and cone photoreceptors were preserved during the course of the 3-mo study. Cone-mediated ERG was stably restored to $\sim 45 \%$ of wild-type. Treated mice also showed cone-mediated visual behavior (optokinetic reflex) that was identical to that seen in wild-type mice. Rod-mediated behavior was not evaluated because of the residual function of this cell type in this model. This was the first demonstration of gene-based restoration of visual function/visually guided behavior and cone preservation in a mammalian model of LCA1, and thus it laid the groundwork for development of an AAV-based gene therapy for treatment of this disease.

Two follow-up studies conducted by Mihelec et al. and Boye et al. evaluated whether AAVmediated gene replacement was therapeutic in the GC1KO mouse for $>3$ mo (Boye et al. 2011; Mihelec et al. 2011). Mihelec et al. demonstrated that an AAV8 vector containing the hGRK1 promoter and human GUCY2D cDNA effectively rescued the $\mathrm{GC1KO}$ mouse phenotype following subretinal injection at P10 (Mihelec et al. 2011). Two vector doses were used: a low dose of $2.1 \times 10^{8} \mathrm{vg}$ delivered and a high dose of $1.2 \times 10^{10} \mathrm{vg}$ delivered. Rescue effects were assayed during the course of 6 mo. GC1 expression was found exclusively in rod/cone outer segments (Mihelec et al. 2011). Cone transducin $\alpha$ expression was increased, its localization to outer segments was restored, and cone photoreceptors were preserved in treated eyes for at least 6 mo (Mihelec et al. 2011). Cone function (as measured by ERG) was restored to $\sim 20 \%$ or $\sim 65 \%$ of wild-type following injection with low and high doses of vector, respectively. Rod function was not improved following treatment with the low dose, but was restored to $65 \%-$ $100 \%$ of wild-type following injection with the high dose of vector (Mihelec et al. 2011). Incorporation of murine Gucy2e cDNA into AAV8hGRK1 led to similar improvements in rod- and cone-mediated function at the high dose. Conemediated visual behavior (optokinetic reflex) was also significantly improved in mice treated with the high dose of vector. It is important to note, given the translational potential of this project, that these robust therapeutic effects were achieved following delivery of the human GUCY2D cDNA (Mihelec et al. 2011).

In the longest follow up reported to date, Boye et al. showed that subretinal delivery of AAV5-smCBA-Gucy2e $\left(4 \times 10^{9}\right.$ vg delivered $)$, AAV5-hGRK1-Gucy2e $\left(4 \times 10^{10}\right.$ vg delivered $)$ and AAV8(Y733F)-hGRK1-Gucy2e $\left(1 \times 10^{10}\right.$ vg delivered) in GC1KO mice (P14-P25) restored retinal function and preserved cone photoreceptors for at least $1 \mathrm{yr}$ after treatment (Boye et al. 2011). The tyrosine capsid mutant AAV8(Y733F) was chosen for its improved performance relative to standard AAV8 or AAV5 in other mouse models of inherited retinal disease (Pang et al. 2011). Cones were preserved and cone-mediated ERGs were stably restored to $\sim 45 \%$ of wild-type following treatment. AAV8(Y733F) mediated more robust ERG improvements than did either AAV5-based vector (Boye et al. 2011). Reasons for this could include the ability of AAV8-based vectors to spread beyond the injection bleb (i.e., a greater percentage of retina was transduced with this serotype) (Stieger et al. 2008), or the relative speed of transgene expression mediated by this serotype (i.e., faster onset of GC1 expression- 
enhanced rescue) (Petrs-Silva et al. 2009; Pang et al. 2011). Between 7 mo and 1 yr posttreatment, optic nerves and brains were analyzed for the presence of AAV5 or AAV8(Y733F) vector genomes. Whereas GC1 expression was restricted to photoreceptor outer segments, both AAV5 and AAV8(Y733F) genomes were detected in optic nerves and, in one case, the brains of treated mice. AAV8(Y733F) genomes were more abundant in the optic nerve, a result likely owed to the increased affinity of this serotype for retinal ganglion cells relative to AAV5 (Surace and Auricchio 2008; Petrs-Silva et al. 2009). Some exposure of vector to ganglion cells is expected as the syringe transverses the inner retina during subretinal injection and also because the ratio of injection volume to total eye size is high in the mouse.

One notable difference between the Boye et al. 2011 and Mihelec et al. studies was the level of functional rescue achieved. Cone-mediated ERG responses were $45 \%$ versus $65 \%$ of normal, respectively (Boye et al. 2011; Mihelec et al. 2011). In addition, only Mihelec et al. reported any significant improvements in rod function (Mihelec et al. 2011). These differences are likely attributed to the age at which therapeutic vector was delivered. Boye et al. administered vector to P14-P25 mice, after their eyes had opened naturally. Mihelec et al. administered vector at P10, before eye opening. Earlier intervention was likely more effective at combating the effects of chronic hyperpolarization that GC1KO photoreceptors endure on light stimulation. Regardless of differences in ERG improvements, treatment of GC1KO mice at all time points, with all serotypes and cDNAs tested, resulted in restoration of useful cone-mediated vision in both studies (Boye et al. 2011; Mihelec et al. 2011). Taken together, these long term studies strongly support further development of an AAV-based gene replacement therapy for LCA1.

\section{GC1/GC2 Double Knockout (GCDKO) Mouse}

The GCDKO mouse was engineered by Baehr et al. to analyze the individual contributions of GC1 and GC2 to phototransduction, and its preliminary natural history was published in 2007 (Table 1) (Baehr et al. 2007). Proof that GC2 supports $30 \%-50 \%$ of rod function and prevents rod degeneration in the GC1KO mouse was found via this model, as deletion of both GC1 and GC2 in the GCDKO mice renders both rod and cone photoreceptors nonfunctional (unrecordable ERG) and degenerative. Both GCAP1 and GCAP2 are down-regulated and mislocalized, and all subunits of cGMP phophodiesterase 6 are absent from GCDKO rods (Baehr et al. 2007). Cones lack cone transducin, cone cGMP phophodiesterase, and GRK1, and opsins are down-regulated and mislocalized. Down-regulation of phototransduction proteins was shown to be posttranslational, suggesting a role for GCs in the stability and/or transport of these proteins. Cone outer segments are unstable and begin to "disintegrate" (extracellular particles immunopositive for cone proteins appear adjacent to the retinal pigment epithelium) at two months of age. Overall outer segment lengths are reduced by $30 \%-50 \%$ in 2-mo-old mice. Appreciable thinning of the outer nuclear layer does not occur until about 3.5 to 4 mo (Boye et al. 2013). By 6 mo, only four to six nuclei remain in the outer nuclear layer (Boye et al. 2013).

The GCDKO mouse is an attractive model in which to evaluate GC1 gene replacement for two reasons. First, before its 2013 clinical characterization (Jacobson et al. 2013), multiple reports described that both cone/rod structure and cone/rod function were compromised in LCA1 (Milam et al. 2003; Porto et al. 2003), suggesting that the best model of this disease was one in which both photoreceptor subclasses were nonfunctional/degenerative. Although the GC1KO mouse is useful for evaluating therapeutic benefit to cones (Boye et al. 2010, 2011; Mihelec et al. 2011), residual rod function and preservation of rod structure in this model complicates the ability to evaluate rod therapy. The GCDKO mouse affords the opportunity to evaluate therapeutic effects on both photoreceptor subclasses. More importantly, because the GCDKO mouse lacks all retinal GC activity, it allows for testing the functional efficiency of AAV-delivered GC1. GC activity assays per- 
S.E. Boye

formed on retinal tissue cannot discriminate between cGMP produced by GC1 versus GC2. Therefore, isolating the functional efficiency of exogenous GC1 requires delivery to photoreceptors that lack endogenous GC1 and GC2. Such analysis in the GCDKO mouse would be useful as a bioassay for evaluating relative potency of clinical vectors.

Boye et al. subretinally delivered AAV (Y733F) containing the hGRK1 promoter and Gucy2e cDNA to GCDKO mice of various ages, ranging from P18-P108 (Boye et al. 2013). Cone-mediated ERG responses were restored to between $29 \%-42 \%$ of wild-type following late (P108) versus early (P18) treatment, respectively. The level of cone function achieved following early treatment is comparable to that achieved in the GC1KO mouse (Boye et al. 2010, 2011, 2013). Rod-mediated ERGs were restored to between $29 \%-44 \%$ of wild-type following late (P108) versus early (P18) treatment, respectively (Boye et al. 2013). This result extends the Mihelec et al. findings (Mihelec et al. 2011) by demonstrating that restoration of rod function is achievable in a model with physiologically "silent" rods. Both cone and rod responses were stable during the course of the long term study ( 1 yr posttreatment). Optokinetic reflex and Morris water maze tests were used to assay the presence of subcortically and cortically driven visual behavior, respectively, in GCDKO mice treated between P18 and P49. Optokinetic testing showed no significant difference in cone-mediated spatial frequency or contrast sensitivity between 1-yr-old treated GCDKO mice and age-matched wild-type controls (Boye et al. 2013). Morris water maze testing revealed no significant difference in coneand rod- mediated behavior between 1-yr-old treated GCDKO mice and age-matched wildtype controls. Taken together, these tests show that postnatal $\mathrm{AAV}-\mathrm{Gucy} 2 e$ treatment restores useful cone and rod-mediated vision in this model of LCA1. As in the GC1KO mouse, wild-type-like behavior was achieved in GCDKO mice that showed only partial ERG recovery. Optical coherence tomography was used to monitor the rate of photoreceptor degeneration in treated and untreated GCDKO and age-matched wild- type controls over time. By 7-12 mo posttreatment, significant structural preservation was seen in all treatment groups, barring the oldest (P108) cohort. Although the difference was not significant following late treatment, outer nuclear layer thickness in this group was still greater than that seen in untreated GCDKO mice. The rate of photoreceptor cell loss in GCDKO mice treated as late as P49 was comparable to the natural rate of loss in age-matched wild-type controls. As before, histological analyses confirmed that GC1 was restricted to photoreceptor outer segments and that cone photoreceptor morphology and density were preserved during the long term. Wild-type-like levels of GCAP1 and GCAP2 expression were observed in a P40-treated GCDKO mouse killed at one year of age, with expression predominantly restricted to photoreceptor outer segments. S-opsin and M-opsin were present in cones of treated mice whereas they were absent from untreated controls.

To determine the functional efficiency of the AAV-delivered GC1 enzyme, GC activity assays were performed using GCDKO retinas treated at $\mathrm{P} 30-\mathrm{P} 60$ with either AAV8(Y733F)Gucy2e or control AAV-GFP, untreated GCDKO retinas and age-matched wild-type control retinas (Boye et al. 2013). Because GC2 is lacking from GCDKO samples, GC activity solely represents the activity of AAV-delivered GC1. Maximal GC activity in treated mice was restored to $\sim 63 \%$ of normal (Boye et al. 2013). If the known contribution of GC2 to total GC activity in wild-type mice-20\%-28\% (Peshenko et al. 2011) - is subtracted from this value, levels of GC1 activity in treated GCDKO mice approach $\sim 90 \%$ of normal. Because the area of AAV-mediated transgene expression in treated retinas is known to correspond to the area of retinal detachment (Timmers et al. 2001; Cideciyan et al. 2008), and because a "good" subretinal injection typically detaches $80 \%-90 \%$ of the retina, this level of GC1 activity suggests near-complete restoration for the area exposed to vector. Normalization of the maximal GC activity in wildtype and AAV-Gucy2e-treated GCDKO mice revealed that the calcium sensitivities for endogenous and exogenous GC were identical (Boye et al. 2013). The functional efficiency of the 
AAV-delivered GC1 enzyme was therefore normal. This assay will likely be used in future experiments to evaluate the functional efficiency of GC1 encoded by human GUCY2D and to establish dose-response relationships in the GCDKO mouse.

\section{CONCLUDING REMARKS}

Several decisions must be made as we move beyond the aforementioned proof-of-concept studies and into the clinic. Which AAV serotype-promoter combination should be used? Which is the preferred injection route? What is the safest and most effective dose?

The answers to the first two questions are inextricably linked. Viral serotype choice is dependent on the route of administration, as transduction profiles vary greatly depending on where the vector is placed within the eye (Dalkara et al. 2009; Vandenberghe and Auricchio 2012). The route of administration is ideally dictated by the structural integrity of the retina, with subretinal injections considered "safer" under relatively less degenerated tissue that is able to withstand the impact of surgical detachment. The notable retinal preservation reported by Jacobson et al. (2013) suggests that LCA1 patients are good candidates for subretinal injection. The AAV serotypes used in proof-of-concept LCA1 studies, AAV5 and AAV8, have proven utility following subretinal injection in various mouse and dog models of photoreceptor-mediated disease (Min et al. 2005; Alexander et al. 2007; Boye et al. 2010, 2013; Gorbatyuk et al. 2010; Komaromy et al. 2010; Mao et al. 2011; Pang et al. 2011, 2012; Yao et al. 2011; Beltran et al. 2012). Because transduction can vary across species, it is essential to evaluate vectors in a species as closely related to man as possible. Toward this end, the transduction profiles of AAV5 and AAV8 have recently been described in nonhuman primates. Keeping in mind that the primary target in LCA1 is the central, cone-rich retina, focus must be placed on each serotype's ability to transduce cone photoreceptors. Only partial cone transduction was achieved following subretinal delivery of elevated doses of AAV8-CMV-GFP $\left(10^{11} \mathrm{vg}\right.$ de- livered) in nonhuman primates (Vandenberghe et al. 2011, 2013). At a lower dose $\left(10^{10} \mathrm{vg}\right.$ delivered), this serotype failed to transduce foveal, parafoveal, or perifoveal cones (Vandenberghe et al. 2011). In contrast, foveal, parafoveal, perifoveal, and peripheral cones of nonhuman primates were all effectively transduced following subretinal delivery of AAV5-hGRK1-GFP $\left(10^{10}\right.$ vg delivered) (Boye et al. 2012). As in rodent retinas (Khani et al. 2007; Tan et al. 2009; Boye et al. 2010, 2011; Pawlyk et al. 2010; Sun et al. 2010), hGRK1 has exclusive activity in cones and rods of nonhuman primates (Boye et al. 2012). Taken together, these results support the use of a subretinally delivered AAV5 vector containing the hGRK1 promoter for delivering GUCY2D in a clinical setting.

Several major differences exist between GUCY2D-LCA1 and the form of this disease currently being treated in clinic (RPE65LCA2). First, a large animal model only exists for the latter. The availability of the RPE65-deficient dog model allowed for correlations to be made between vector dose, efficacy, toxicity, and biodistribution (spread of vector genomes beyond the subretinal space) in an organism relatively similar in size (Jacobson et al. 2006a). This formed the framework for safety studies performed in normal nonhuman primates in which relationships between vector dose and toxicity/ biodistribution were evaluated (Jacobson et al. 2006b). For LCA1, correlations between vector dose and efficacy are currently limited to the GC1KO and/or GCDKO mouse models. As in LCA2, relationships between vector dose and toxicity/biodistribution must be determined in nonhuman primates.

Another major difference between LCA1 and LCA2 is the disease target. LCA2 arises from defects in a protein expressed exclusively in the retinal pigment epithelium (RPE65). Of the proteins encoded by genes known to be associated with LCA -18 to date (den Hollander et al. 2008; Wang et al. 2009; Estrada-Cuzcano et al. 2011; Sergouniotis et al. 2011)—only a minority (four) are specific to the retinal pigment epithelium. The majority of LCAs (13 out of 18) are caused by defects in genes that encode photoreceptor specific proteins. More broadly, 
S.E. Boye

the majority of inherited retinal diseases are caused by defects in proteins expressed in photoreceptors (Wright et al. 2010), a cell type yet to be targeted in a clinical setting. Thus, developing a treatment for GUCY2D-LCA1 will serve as a framework for other photoreceptor-targeted gene replacement strategies.

The primary functional deficit in LCA1 (cone-mediated vision) differs from that of LCA2 (rod-mediated vision). The majority of LCA1 patients lack cone function and show severe loss of visual acuity, despite retaining foveal architecture. It is unclear how amblyopia (the inability of the retina to send visual information to the brain) in both eyes will affect patients' responses to GUCY2D gene replacement. It is possible that gene therapy will restore the cones' ability to reset their sensitivity (return to the dark state)/depolarize, but that this information will not be properly relayed to visual processing centers of the brain. Understanding how brains of LCA1 patients, the majority of whom have functionally silent cones, will accommodate GUCY2D gene replacement will only be accomplished through a clinical trial.

\section{ACKNOWLEDGMENTS}

I would like to thank Sanford L. Boye, M.S. for his thoughtful critique of this collection article and Jim Peterson, Ph.D., RN for his assistance with immunohistochemical analysis of the primate retina.

\section{REFERENCES}

Alexander JJ, Umino Y, Everhart D, Chang B, Min SH, Li Q, Timmers AM, Hawes NL, Pang JJ, Barlow RB, et al. 2007. Restoration of cone vision in a mouse model of achromatopsia. Nat Med 13: 685-687.

Arshavsky VY, Burns ME. 2012. Photoreceptor signaling: Supporting vision across a wide range of light intensities. J Biol Chem 287: 1620-1626.

Baehr W, Karan S, Maeda T, Luo DG, Li S, Bronson JD, Watt CB, Yau KW, Frederick JM, Palczewski K. 2007. The function of guanylate cyclase 1 and guanylate cyclase 2 in rod and cone photoreceptors. J Biol Chem 282: 8837-8847.

Bainbridge JW, Stephens C, Parsley K, Demaison C, Halfyard A, Thrasher AJ, Ali RR. 2001. In vivo gene transfer to the mouse eye using an HIV-based lentiviral vector; efficient long-term transduction of corneal endothelium and retinal pigment epithelium. Gene Ther 8: $1665-$ 1668.
Beltran WA, Cideciyan AV, Lewin AS, Iwabe S, Khanna H, Sumaroka A, Chiodo VA, Fajardo DS, Roman AJ, Deng WT, et al. 2012. Gene therapy rescues photoreceptor blindness in dogs and paves the way for treating human X-linked retinitis pigmentosa. Proc Natl Acad Sci 109: 2132-2137.

Boye SE, Boye SL, Pang J, Ryals R, Everhart D, Umino Y, Neeley AW, Besharse J, Barlow R, Hauswirth WW. 2010. Functional and behavioral restoration of vision by gene therapy in the guanylate cyclase-1 (GC1) knockout mouse. PLOS ONE 5: el1306.

Boye SL, Conlon T, Erger K, Ryals R, Neeley A, Cossette T, Pang J, Dyka FM, Hauswirth WW, Boye SE. 2011. Longterm preservation of cone photoreceptors and restoration of cone function by gene therapy in the guanylate cyclase1 knockout (GC1KO) mouse. Invest Ophthalmol Vis Sci 52: 7098-7108.

Boye SE, Alexander JJ, Boye SL, Witherspoon CD, Sandefer KJ, Conlon TJ, Erger K, Sun J, Ryals R, Chiodo VA, et al. 2012. The human rhodopsin kinase promoter in an AAV5 vector confers rod- and cone-specific expression in the primate retina. Hum Gene Ther 23: 1101-1115.

Boye SL, Peshenko IV, Huang WC, Min SH, McDoom I, Kay CN, Liu X, Dyka FM, Foster TC, Umino Y, et al. 2013. AAV-mediated gene therapy in the guanylate cyclase (RetGC1/RetGC2) double knockout mouse model of Leber congenital amaurosis. Hum Gene Ther 24: 189202.

Burns ME, Arshavsky VY. 2005. Beyond counting photons: Trials and trends in vertebrate visual transduction. Neuron 48: $387-401$.

Chung DC, Traboulsi EI. 2009. Leber congenital amaurosis: Clinical correlations with genotypes, gene therapy trials update, and future directions. J AAPOS 13: 587-592.

Cheng KM, Shoffner RN, Gelatt KN, Gum GG, Otis JS, Bitgood JJ. 1980. An autosomal recessive blind mutant in the chicken. Poult Sci 59: 2179-2181.

Cideciyan AV, Aleman TS, Jacobson SG, Khanna H, Sumaroka A, Aguirre GK, Schwartz SB, Windsor EA, He S, Chang B, et al. 2007. Centrosomal-ciliary gene CEP290/ NPHP6 mutations result in blindness with unexpected sparing of photoreceptors and visual brain: Implications for therapy of Leber congenital amaurosis. Hum Mutat 28: $1074-1083$.

Cideciyan AV, Aleman TS, Boye SL, Schwartz SB, Kaushal S, Roman AJ, Pang JJ, Sumaroka A, Windsor EA, Wilson JM, et al. 2008. Human gene therapy for RPE65 isomerase deficiency activates the retinoid cycle of vision but with slow rod kinetics. Proc Natl Acad Sci 105: 15112 15117.

Cideciyan AV, Hauswirth WW, Aleman TS, Kaushal S, Schwartz SB, Boye SL, Windsor EA, Conlon TJ, Sumaroka A, Roman AJ, et al. 2009. Vision 1 year after gene therapy for Leber's congenital amaurosis. $N$ Engl J Med 361: 725-727.

Cideciyan AV, Swider M, Aleman TS, Feuer WJ, Schwartz SB, Russell RC, Steinberg JD, Stone EM, Jacobson SG. 2012. Macular function in macular degenerations: Repeatability of microperimetry as a potential outcome measure for ABCA4-associated retinopathy trials. Invest Ophthalmol Vis Sci 53: 841-852. 
Coleman JE, Semple-Rowland SL. 2005. GC1 deletion prevents light-dependent arrestin translocation in mouse cone photoreceptor cells. Invest Ophthalmol Vis Sci 46: $12-16$.

Coleman JE, Zhang Y, Brown GA, Semple-Rowland SL 2004. Cone cell survival and downregulation of GCAP1 protein in the retinas of $\mathrm{GC} 1$ knockout mice. Invest Oph thalmol Vis Sci 45: 3397-3403.

Dalkara D, Kolstad KD, Caporale N, Visel M, Klimczak RR, Schaffer DV, Flannery JG. 2009. Inner limiting membrane barriers to AAV-mediated retinal transduction from the vitreous. Mol Ther 17: 2096-2102.

den Hollander AI, Roepman R, Koenekoop RK, Cremers FP. 2008. Leber congenital amaurosis: Genes, proteins and disease mechanisms. Prog Retin Eye Res 27: 391-419.

Dizhoor AM, Lowe DG, Olshevskaya EV, Laura RP, Hurley JB. 1994. The human photoreceptor membrane guanylyl cyclase, RetGC, is present in outer segments and is regulated by calcium and a soluble activator. Neuron $\mathbf{1 2}$ 1345-1352.

Dizhoor AM, Olshevskaya EV, Henzel WJ, Wong SC, Stults JT, Ankoudinova I, Hurley JB. 1995. Cloning, sequencing, and expression of a $24-\mathrm{kDa} \mathrm{Ca}^{2+}$-binding protein activating photoreceptor guanylyl cyclase. J Biol Chem 270: 25200-25206.

Estrada-Cuzcano A, Koenekoop RK, Coppieters F, Kohl S, Lopez I, Collin RW, De Baere EB, Roeleveld D, Marek J, Bernd A, et al. 2011. IQCB1 mutations in patients with Leber congenital amaurosis. Invest Ophthalmol Vis Sci 52: 834-839.

Gorbatyuk MS, Knox T, LaVail MM, Gorbatyuk SS, Noorwez SM, Hauswirth WW, Lin JH, Muzyczka N, Lewin AS. 2010. Restoration of visual function in $\mathrm{P} 23 \mathrm{H}$ rhodopsin transgenic rats by gene delivery of $\mathrm{BiP} / \mathrm{Grp78}$. Proc Natl Acad Sci 107: 5961-5966.

Gorczyca WA, Polans AS, Surgucheva IG, Subbaraya I, Baehr W, Palczewski K. 1995. Guanylyl cyclase activating protein. A calcium-sensitive regulator of phototransduction. J Biol Chem 270: 22029-22036.

Haire SE, Pang J, Boye SE, Sokal I, Craft CM, Palczewski K, Hauswirth WW, Semple-Rowland SL. 2006. Light-driven cone arrestin translocation in cones of postnatal guanylate cyclase- 1 knockout mouse retina treated with AAVGC1. Invest Ophthalmol Vis Sci 47: 3745-3753.

Hwang JY, Lange C, Helten A, Hoppner-Heitmann D, Duda T, Sharma RK, Koch KW. 2003. Regulatory modes of rod outer segment membrane guanylate cyclase differ in catalytic efficiency and $\mathrm{Ca}^{2+}$-sensitivity. Eur J Biochem 270: 3814-3821.

Jacobson SG, Cideciyan AV, Huang Y, Hanna DB, Freund CL, Affatigato LM, Carr RE, Zack DJ, Stone EM, McInnes RR. 1998. Retinal degenerations with truncation mutations in the cone-rod homeobox $(C R X)$ gene. Invest Ophthalmol Vis Sci 39: 2417-2426.

Jacobson SG, Cideciyan AV, Aleman TS, Pianta MJ, Sumaroka A, Schwartz SB, Smilko EE, Milam AH, Sheffield VC, Stone EM. 2003. Crumbs homolog 1 (CRB1) mutations result in a thick human retina with abnormal lamination. Hum Mol Genet 12: 1073-1078.

Jacobson SG, Aleman TS, Cideciyan AV, Sumaroka A, Schwartz SB, Windsor EA, Traboulsi EI, Heon E, Pittle SJ, Milam AH, et al. 2005. Identifying photoreceptors in blind eyes caused by RPE65 mutations: Prerequisite for human gene therapy success. Proc Natl Acad Sci 102: 6177-6182.

Jacobson SG, Acland GM, Aguirre GD, Aleman TS, Schwartz SB, Cideciyan AV, Zeiss CJ, Komaromy AM, Kaushal S, Roman AJ, et al. 2006a. Safety of recombinant adeno-associated virus type 2-RPE65 vector delivered by ocular subretinal injection. Mol Ther 13: 1074-1084.

Jacobson SG, Boye SL, Aleman TS, Conlon TJ, Zeiss CJ, Roman AJ, Cideciyan AV, Schwartz SB, Komaromy AM, Doobrajh M, et al. 2006b. Safety in nonhuman primates of ocular AAV2-RPE65, a candidate treatment for blindness in Leber congenital amaurosis. Hum Gene Ther 17: 845-858.

Jacobson SG, Cideciyan AV, Aleman TS, Sumaroka A, Schwartz SB, Roman AJ, Stone EM. 2007a. Leber's congenital amaurosis caused by an RPGRIP1 mutation shows treatment potential. Ophthalmology 114: 895-898.

Jacobson SG, Cideciyan AV, Aleman TS, Sumaroka A, Schwartz SB, Windsor EA, Roman AJ, Heon E, Stone EM, Thompson DA. 2007b. RDH12 and RPE65, visual cycle genes causing Leber congenital amaurosis, differ in disease expression. Invest Ophthalmol Vis Sci 48: $332-$ 338.

Jacobson SG, Aleman TS, Cideciyan AV, Sumaroka A, Schwartz SB, Windsor EA, Swider M, Herrera W, Stone EM. 2009. Leber congenital amaurosis caused by Lebercilin (LCA5) mutation: Retained photoreceptors adjacent to retinal disorganization. Mol Vis 15: 1098-1106.

Jacobson SG, Cideciyan AV, Aleman TS, Sumaroka A, Roman AJ, Swider M, Schwartz SB, Banin E, Stone EM. 2011. Human retinal disease from AIPL1 gene mutations: Foveal cone loss with minimal macular photoreceptors and rod function remaining. Invest Ophthalmol Vis Sci 52: 70-79.

Jacobson SG, Cideciyan AV, Peshenko IV, Sumaroka A, Olshevskaya EV, Cao L, Schwartz SB, Roman AJ, Olivares MB, Sadigh S, et al. 2013. Determining consequences of retinal membrane guanylyl cyclase (RetGC1) deficiency in human Leber congenital amaurosis en route to therapy: Residual cone-photoreceptor vision correlates with biochemical properties of the mutants. Hum Mol Genet 22: $168-183$.

Khani SC, Pawlyk BS, Bulgakov OV, Kasperek E, Young JE, Adamian M, Sun X, Ali RR, Li T. 2007. AAV-mediated expression targeting of rod and cone photoreceptors with a human rhodopsin kinase promoter. Invest Ophthalmol Vis Sci 48: 3954-3961.

Komaromy AM, Alexander JJ, Rowlan JS, Garcia MM, Chiodo VA, Kaya A, Tanaka JC, Acland GM, Hauswirth WW, Aguirre GD. 2010. Gene therapy rescues cone function in congenital achromatopsia. Hum Mol Genet 19: 2581-2593.

Liu X, Seno K, Nishizawa Y, Hayashi F, Yamazaki A, Matsumoto H, Wakabayashi T, Usukura J. 1994. Ultrastructural localization of retinal guanylate cyclase in human and monkey retinas. Exp Eye Res 59: 761-768.

Lowe DG, Dizhoor AM, Liu K, Gu Q, Spencer M, Laura R, Lu L, Hurley JB. 1995. Cloning and expression of a second photoreceptor-specific membrane retina guanylyl cyclase (RetGC), RetGC-2. Proc Natl Acad Sci 92: 5535-5539. 
S.E. Boye

Mao H, James T Jr, Schwein A, Shabashvili AE, Hauswirth WW, Gorbatyuk MS, Lewin AS. 2011. AAV delivery of wild-type rhodopsin preserves retinal function in a mouse model of autosomal dominant retinitis pigmentosa. Hum Gene Ther 22: 567-575.

Mihelec M, Pearson RA, Robbie SJ, Buch PK, Azam SA, Bainbridge JW, Ali RR. 2011. Long-term preservation of cones and improvement in visual function following gene therapy in a mouse model of Leber congenital amaurosis caused by guanylate cyclase-1 deficiency. Hum Gene Ther 22: 1179-1190.

Milam AH, Barakat MR, Gupta N, Rose L, Aleman TS, Pianta MJ, Cideciyan AV, Sheffield VC, Stone EM, Jacobson SG. 2003. Clinicopathologic effects of mutant GUCY2D in Leber congenital amaurosis. Ophthalmology 110: $549-558$.

Min SH, Molday LL, Seeliger MW, Dinculescu A, Timmers AM, Janssen A, Tonagel F, Tanimoto N, Weber BH, Molday RS, et al. 2005. Prolonged recovery of retinal structure/function after gene therapy in an Rslh-deficient mouse model of X-linked juvenile retinoschisis. $\mathrm{Mol}$ Ther 12: 644-651.

Miyoshi H, Takahashi M, Gage RH, Verma IM. 1997. Stable and efficient gene transfer into the retina using an HIVbased lentiviral vector. Proc Natl Acad Sci 94: 1031910323.

Olshevskaya EV, Peshenko IV, Savchenko AB, Dizhoor AM. 2012. Retinal guanylyl cyclase isozyme 1 is the preferential in vivo target for constitutively active GCAP1 mutants causing congenital degeneration of photoreceptors. $J$ Neurosci 32: 7208-7217.

Pang J, Cheng M, Haire SE, Barker E, Planelles V, Blanks JC. 2006. Efficiency of lentiviral transduction during development in normal and $r d$ mice. Mol Vis 12: 756-767.

Pang JJ, Dai X, Boye SE, Barone I, Boye SL, Mao S, Everhart D, Dinculescu A, Liu L, Umino Y, et al. 2011. Long-term retinal function and structure rescue using capsid mutant AAV8 vector in the $r d 10$ mouse, a model of recessive retinitis pigmentosa. Mol Ther 19: 234-242.

Pang JJ, Deng WT, Dai X, Lei B, Everhart D, Umino Y, Li J, Zhang K, Mao S, Boye SL, et al. 2012. AAV-mediated cone rescue in a naturally occurring mouse model of CNGA3achromatopsia. PLoS ONE 7: e35250.

Pasadhika S, Fishman GA, Stone EM, Lindeman M, Zelkha R, Lopez I, Koenekoop RK, Shahidi M. 2010. Differential macular morphology in patients with RPE65-, CEP290-, GUCY2D-, and AIPL1-related Leber congenital amaurosis. Invest Ophthalmol Vis Sci 51: 2608-2614.

Pawlyk BS, Bulgakov OV, Liu X, Xu X, Adamian M, Sun X, Khani SC, Berson EL, Sandberg MA, Li T. 2010. Replacement gene therapy with a human RPGRIP1 sequence slows photoreceptor degeneration in a murine model of Leber congenital amaurosis. Hum Gene Ther 21: $993-$ 1004.

Perrault I, Rozet JM, Calvas P, Gerber S, Camuzat A, Dollfus H, Chatelin S, Souied E, Ghazi I, Leowski C, et al. 1996. Retinal-specific guanylate cyclase gene mutations in Leber's congenital amaurosis. Nat Genet 14: 461-464.

Perrault I, Rozet JM, Gerber S, Ghazi I, Leowski C, Ducroq D, Souied E, Dufier JL, Munnich A, Kaplan J. 1999. Leber congenital amaurosis. Mol Genet Metab 68: 200-208.
Perrault I, Rozet JM, Gerber S, Ghazi I, Ducroq D, Souied E, Leowski C, Bonnemaison M, Dufier JL, Munnich A, et al. 2000. Spectrum of retGC1 mutations in Leber's congenital amaurosis. Eur J Hum Genet 8: 578-582.

Peshenko IV, Dizhoor AM. 2004. Guanylyl cyclase-activating proteins (GCAPs) are $\mathrm{Ca}^{2+} / \mathrm{Mg}^{2+}$ sensors: Implications for photoreceptor guanylyl cyclase (RetGC) regulation in mammalian photoreceptors. J Biol Chem 279: 16903-16906.

Peshenko IV, Olshevskaya EV, Savchenko AB, Karan S, Palczewski K, Baehr W, Dizhoor AM. 2011. Enzymatic properties and regulation of the native isozymes of retinal membrane guanylyl cyclase (RetGC) from mouse photoreceptors. Biochemistry 50: 5590-5600.

Petrs-Silva H, Dinculescu A, Li Q, Min SH, Chiodo V, Pang JJ, Zhong L, Zolotukhin S, Srivastava A, Lewin AS, et al. 2009. High-efficiency transduction of the mouse retina by tyrosine-mutant AAV serotype vectors. Mol Ther 17: 463-471.

Polans A, Baehr W, Palczewski K. 1996. Turned on by $\mathrm{Ca}^{2+}$ ! The physiology and pathology of $\mathrm{Ca}^{2+}$-binding proteins in the retina. Trends Neurosci 19: 547-554.

Porto FB, Perrault I, Hicks D, Rozet JM, Hanoteau N, Hanein S, Kaplan J, Sahel JA. 2003. Prenatal human ocular degeneration occurs in Leber's congenital amaurosis (LCA1 and 2). Adv Exp Med Biol 533: 59-68.

Semple-Rowland SL, Berry J. 2013. Use of lentiviral vectors to deliver and express bicistronic transgenes in developing chicken embryos. Methods 66: 466-473.

Semple-Rowland SL, Lee NR, Van Hooser JP, Palczewski K, Baehr W. 1998. A null mutation in the photoreceptor guanylate cyclase gene causes the retinal degeneration chicken phenotype. Proc Natl Acad Sci 95: 1271-1276.

Sergouniotis PI, Davidson AE, Mackay DS, Li Z, Yang X, Plagnol V, Moore AT, Webster AR. 2011. Recessive mutations in KCNJ13, encoding an inwardly rectifying potassium channel subunit, cause Leber congenital amaurosis. Am J Hum Genet 89: 183-190.

Simonelli F, Ziviello C, Testa F, Rossi S, Fazzi E, Bianchi PE, Fossarello M, Signorini S, Bertone C, Galantuomo S, et al. 2007. Clinical and molecular genetics of Leber's congenital amaurosis: A multicenter study of Italian patients. Invest Ophthalmol Vis Sci 48: 4284-4290.

Stieger K, Colle MA, Dubreil L, Mendes-Madeira A, Weber M, Le MG, Deschamps JY, Provost N, Nivard D, Cherel Y, et al. 2008. Subretinal delivery of recombinant AAV serotype 8 vector in dogs results in gene transfer to neurons in the brain. Mol Ther 16: 916-923.

Sun X, Pawlyk B, Xu X, Liu X, Bulgakov OV, Adamian M, Sandberg MA, Khani SC, Tan MH, Smith AJ, et al. 2010. Gene therapy with a promoter targeting both rods and cones rescues retinal degeneration caused by AIPL1 mutations. Gene Ther 17: 117-131.

Surace EM, Auricchio A. 2008. Versatility of AAV vectors for retinal gene transfer. Vision Res 48: 353-359.

Tan MH, Smith AJ, Pawlyk B, Xu X, Liu X, Bainbridge JB, Basche M, McIntosh J, Tran HV, Nathwani A, et al. 2009. Gene therapy for retinitis pigmentosa and Leber congenital amaurosis caused by defects in AIPL1: Effective rescue of mouse models of partial and complete Aipll deficiency using AAV2 $/ 2$ and AAV2/8 vectors. Hum Mol Genet 18: 2099-2114. 
Timmers AM, Zhang H, Squitieri A, Gonzalez-Pola C. 2001 Subretinal injections in rodent eyes: Effects on electrophysiology and histology of rat retina. Mol Vis 7: 131-137.

Ulshafer RJ, Allen CB. 1985a. Hereditary retinal degeneration in the Rhode Island Red chicken: Ultrastructural analysis. Exp Eye Res 40: 865-877.

Ulshafer RJ, Allen CB. 1985b. Ultrastructural changes in the retinal pigment epithelium of congenitally blind chickens. Curr Eye Res 4: 1009-1021.

Ulshafer RJ, Allen C, Dawson WW, Wolf ED. 1984. Hereditary retinal degeneration in the Rhode Island Red chicken: I. Histology and ERG. Exp Eye Res 39: 125-135.

Vandenberghe LH, Auricchio A. 2012. Novel adeno-associated viral vectors for retinal gene therapy. Gene Ther 19: $162-168$.

Vandenberghe LH, Bell P, Maguire AM, Cearley CN, Xiao R, Calcedo R, Wang L, Castle MJ, Maguire AC, Grant R, et al. 2011. Dosage thresholds for AAV2 and AAV8 photoreceptor gene therapy in monkey. Sci Transl Med 3: 88ra54.

Vandenberghe LH, Bell P, Maguire AM, Xiao R, Hopkins TB, Grant R, Bennett J, Wilson JM. 2013. AAV9 targets cone photoreceptors in the nonhuman primate retina. PLoS ONE 8: e53463.

Verrier JD, Madorsky I, Coggin WE, Geesey M, Hochman M, Walling E, Daroszewski D, Eccles KS, Ludlow R, Semple-Rowland SL. 2011. Bicistronic lentiviruses containing a viral $2 \mathrm{~A}$ cleavage sequence reliably co-express two proteins and restore vision to an animal model of LCA1. PLoS ONE 6: e20553.

Wallman J, Velez J. 1985. Directional asymmetries of optokinetic nystagmus: Developmental changes and relation to the accessory optic system and to the vestibular system. J Neurosci 5: 317-329.

Wang H, den Hollander AI, Moayedi Y, Abulimiti A, Li Y, Collin RW, Hoyng CB, Lopez I, Abboud EB, Al-Rajhi AA, et al. 2009. Mutations in SPATA7 cause Leber congenital amaurosis and juvenile retinitis pigmentosa. Am J Hum Genet 84: 380-387.

Williams ML, Coleman JE, Haire SE, Aleman TS, Cideciyan AV, Sokal I, Palczewski K, Jacobson SG, Semple-Rowland SL. 2006. Lentiviral expression of retinal guanylate cyclase-1 (RetGC1) restores vision in an avian model of childhood blindness. PLoS Med 3: e201.

Wright AF, Chakarova CF, Abd El-Aziz MM, Bhattacharya SS. 2010. Photoreceptor degeneration: Genetic and mechanistic dissection of a complex trait. Nat Rev Genet 11: $273-284$.

Yang RB, Robinson SW, Xiong WH, Yau KW, Birch DG, Garbers DL. 1999. Disruption of a retinal guanylyl cyclase gene leads to cone-specific dystrophy and paradoxical rod behavior. J Neurosci 19: 5889-5897.

Yang GS, Schmidt M, Yan Z, Lindbloom JD, Harding TC, Donahue BA, Engelhardt JF, Kotin R, Davidson BL. 2002. Virus-mediated transduction of murine retina with adeno-associated virus: Effects of viral capsid and genome size. J Virol 76: 7651-7660.

Yao J, Feathers KL, Khanna H, Thompson D, Tsilfidis C, Hauswirth WW, Heckenlively JR, Swaroop A, Zacks DN. 2011. XIAP therapy increases survival of transplanted rod precursors in a degenerating host retina. Invest Ophthalmol Vis Sci 52: 1567-1572. 


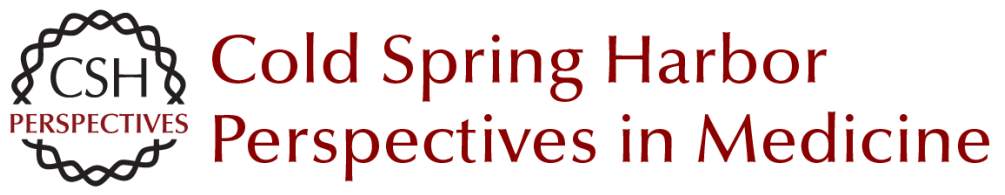

\section{Leber Congenital Amaurosis Caused by Mutations in GUCY2D}

Shannon E. Boye

Cold Spring Harb Perspect Med 2015; doi: 10.1101/cshperspect.a017350 originally published online September 25, 2014

\section{Subject Collection Retinal Disorders: Genetic Approaches to Diagnosis and Treatment}

Trial by "Firsts": Clinical Trial Design and Regulatory Considerations in the Development and Approval of the First AAV Gene Therapy Product in the United States

Kathleen Z. Reape and Katherine A. High

Immunology of Retinitis Pigmentosa and Gene Therapy-Associated Uveitis

Paul Yang, Debarshi Mustafi and Kathryn L. Pepple

Developing New Vectors for Retinal Gene Therapy Emilia A. Zin, Bilge E. Ozturk, Deniz Dalkara, et al.

Beyond the NEI-VFQ: Recent Experience in the Development and Utilization of Patient-Reported Outcomes for Inherited Retinal Diseases

Todd Durham, Judit Banhazi, Francesco Patalano, et al.

Electronic Retinal Prostheses

Daniel Palanker

Alternative RNA Splicing in the Retina: Insights and Perspectives

Casey J. Keuthan, Sadik Karma and Donald J. Zack

X-Linked Retinoschisis

Cristy A. Ku, Lisa W. Wei and Paul A. Sieving

A Systematic Review of Optogenetic Vision Restoration: History, Challenges, and New Inventions from Bench to Bedside

Antonia Stefanov and John G. Flannery
Lessons Learned from the Development of the First FDA-Approved Gene Therapy Drug, Voretigene Neparvovec-rzyl Jean Bennett and Albert M. Maguire

Therapeutic Gene Editing in Inherited Retinal Disorders Jinjie Ling, Laura A. Jenny, Ashley Zhou, et al.

Cell-Based Therapies: Strategies for Regeneration Marina Pavlou and Thomas A. Reh

The Importance of Natural History Studies in Inherited Retinal Diseases Allison Ayala, Janet Cheetham, Todd Durham, et al.

Photoreceptor Cell Replacement Using Pluripotent Stem Cells: Current Knowledge and Remaining Questions

Christelle Monville, Olivier Goureau and Karim Ben M'Barek

iPSC-RPE in Retinal Degeneration: Recent

Advancements and Future Perspectives

Tadao Maeda and Masayo Takahashi

Retinal Degeneration Animal Models in Bardet-

Biedl Syndrome and Related Ciliopathies Clarisse Delvallée and Hélène Dollfus

Mobility Testing and Other Performance-Based Assessments of Functional Vision in Patients with Inherited Retinal Disease

Daniel Chung, Colas Authié and Laure Blouin

For additional articles in this collection, see http://perspectivesinmedicine.cshlp.org/cgi/collection/ 
For additional articles in this collection, see http://perspectivesinmedicine.cshlp.org/cgi/collection/ 